\title{
Accreditation Of Prior Experiential Learning As A Catalyst For Lifelong Learning: Analysis And Proposals Based On French Experiments
}

Pierre-Yves Sanséau, Grenoble Ecole de Management, France Sandrine Ansart, Grenoble Ecole de Management, France

\begin{abstract}
In this paper, the researchers analyse how lifelong learning can be enriched and develop a different perspective based on the experiment involving the accreditation of prior experiential learning (APEL) conducted in France at the university level. The French system for the accreditation of prior experiential learning, called Validation des Acquis de l'Expérience (VAE), accredits prior learning from past experiences (professional and otherwise) and can lead to full university degrees or diplomas. A literature review on lifelong learning shows that worldwide, it is based on different conceptions and approaches, according to the realities of the education and labour systems and the relationship between them. The researchers note however that work experience is less valued than the acquisition of new and complementary knowledge.
\end{abstract}

Studies on VAE in France in higher education show that a thorough analysis of prior experiential learning: first, improves the quality of the experience as a potential source of skills; second, may provide ways to improve the candidate's experiential learning, and third, may help define the direction for lifelong learning. Therefore, recognition of this experiential learning could be a key catalyst for lifelong learning. The findings support two main arguments advocating a central role for the recognition of prior experiential learning in the lifelong learning process particularly in France: potentially individualized learning paths, personal empowerment and shorter training times; and a focus on experience - and not just professional experience - that is in tune with today's societal changes and the aspirations/constraints of each individual.

Keywords: Lifelong Learning; Prior Experience Learning; APEL; VAE; France

\section{INTRODUCTION}

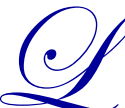

ifelong learning is recognized as having a vital role in employment and education policies. Lifelong learning can take many forms in different countries: learning through courses, work-based learning, experience gained through leisure activities and volunteer work, etc. Since the 1970-1980s, a new direction has emerged, namely the recognition of prior learning or prior experiential learning. This involves the recognition, validation and accreditation, in the form of a certificate or a degree, of knowledge and skills acquired primarily through work experience (Colardyn \& Bjornavold, 2004; Duchemin \& Hawley, 2010).

In this paper, the researchers will analyse and discuss how accreditation of prior experiential learning can support and strengthen lifelong learning, in a university context, based on the French system of VAE established in 2002. An analysis of this system, especially in the French context, provides food for thought about the place of work experience in lifelong learning, the links between work experience, higher education and lifelong learning, and finally the meaning and organisation of lifelong learning. This contextual dimension is important. In fact, it appears that in France, if accreditation of prior experiential learning is linked with employability, its relation with lifelong 
learning is not obvious, contrary to what is supported by the Bologna process (Education, Audiovisual and Culture Executive Agency, 2012).

In the first section, we review the literature to describe the emergence and development of lifelong learning, as well as its objectives in different national, educational and public policy contexts. The concept of recognition of prior experiential learning is also introduced with a particular focus on the situation in France. Research questions and problem statement are presented in the second section, and in the third section, an analysis of the major issues that have emerged from the French VAE experience in higher education is developed. In the fourth section, we discuss the recognition of experiential learning as a central and potentially defining component of lifelong learning.

\section{LITERATURE REVIEW}

\section{Lifelong Learning}

The concept of lifelong learning has developed considerably over the last thirty years in Western countries, in response to a fast-changing environment (Watts \& Fretwell, 2004; Watts, 2005, Tuschling \& Engemann, 2006), in a context of globalization of markets and activities, increasing competition between countries, extremely rapid technological developments and the emergence of the knowledge economy. To supplement or support initial training, multiple approaches such as continuing education, career development and skills development have been developed to overcome the problem of rapid skills obsolescence among the workforce (Colardyn \& Bjornavold, 2004; Arulampalam et al., 2004; Watts \& Sultana, 2004). Lifelong learning is defined as: "All learning activities undertaken throughout life, with the aim of providing knowledge, skills and competencies with a personal, civil, social and/or employment-related perspective" (European commission Directorate-general for education and culture, 2002:7).

In different countries, this new Lifelong Learning approach has developed amid different realities. However, one common finding has emerged: initial training has become insufficient to satisfy the increasing need for skills. International awareness of this issue is high, as evidenced by the three successive studies conducted by the OECD, the World Bank and the European Union (OECD, 2004; Watts \& Fretwell, 2004; Sultana, 2004), and certain policy orientations have also been criticised (Lee \& Friedrich., 2011). Initial training acquired in higher education has become a foundation that is necessary but often insufficient to enable people to succeed on the labour market and remain employable throughout life. This is particularly true in France where diplomas have a major recognition on the work market. This foundation must be supplemented and enriched by continuous acquisition of new knowledge and skills, in a system allowing employed people to continue to learn, understand and develop new specialized knowledge. Today's societies are knowledge societies where knowledge is a central issue (OECD, 2000, 2004).

For adults, the conclusion is clear: they must by necessity or by choice, constantly learn new theories and practices. Indeed, in the new context, they have to constantly redefine their professional roles, reflect on their personal journeys and their careers and upgrade their knowledge bases and skills. The increasing numbers of adults in higher education is probably one of the best illustrations of the knowledge society, which is based on the idea that individual and societal dynamics are nourished through lifelong learning and continuing education (Müller et al., 2003; Papastamatis \& Panitsidou, 2009).

The main societal factors that have led to the greater numbers of adult learners and the need to develop lifelong learning are the following ones: the aging of the active population, with a lower percentage of 18-30 yearolds in the workforce in most Western countries, resulting in a deficit of knowledge and skills; the increasing need for new knowledge in adult populations, given the context of the information and communication society; the frequent technological revolutions especially in information and communication technologies, in connection with the previous factor; the changing expectations and needs in terms of equality and fairness for women, precarious workers and social and ethnic minorities; the context of increased economic competition in a globalized economy, increased trade and movement of people, capital and goods (Watts \& Sultana, 2004; Watts, 2005; Werquin, 2010). 


\section{Public Policy Objectives}

Against this background, countries have implemented various public policies encouraging the development of career guidance services closely related to lifelong learning and the concept of employability.

These public policies have three main objectives. The first is an objective of knowledge acquisition and learning, which includes improving the education and training system to better match the labour market. This is a key point if individuals are to find meaning in the process and if we want a real return on investment at a national level. The second objective is to meet labour market requirements by matching supply to demand and making adjustments as necessary. If individuals find jobs that match their skills, potential and aspirations, they are likely to be more motivated and more productive. The third objective involves social equity, through equal opportunities and social integration. We must help members of disadvantaged groups to promote their aspirations towards opportunities they would otherwise be denied (Stenfors-Hayes et al., 2008; Watts, 2005; OECD, 2004).

The spirit of these policies reflects the paradigm shift that occurred in the late 1990s on the nature of work, career and lifelong learning. In the past, individuals had a "career" in a hierarchical progression model inherited from the industrial era. Today each individual is fully in charge of his or her own evolution. In a context of continuous change, it is not employment that is the key issue, but employability. To maintain and develop employability, one solution is lifelong learning. These solutions can be local or more global. In Europe, for example, the Bologna process (based on the Bologna Declaration of 1999) has 47 countries participating in an intergovernmental process for modernising higher education. The Bologna Process aims to create a European Higher Education Area by 2010, including a focus on lifelong learning (Duchemin \& Hawley, 2010).

\section{Multiple Approaches and Two Models}

At the international level, different terms and definitions are used to refer to lifelong learning in different national and academic contexts. This diverse terminology results from three concomitant factors (Kasworm, 1993). The first is the changing policies defining the relationships between adult continuing education and higher education programs and the resulting new terms to describe this type of training. The second factor reflects the significant differences between national systems of higher education involving many innovative programs and practices. Finally, the international literature in higher education and adult education science contains diverse terminology, because researchers have created new definitions and classifications to include conceptual discussions that are rooted in the multiple realities.

National differences in adult education correspond to each country's culture of education and training, education system, labour market and social and societal values. According to Wolbers (2005), there are two adult education models, which differ in their relationships with the initial training system and the labour market institutions. It is therefore important to define the relationship between so-called general or initial training and vocational training.

The first model considers lifelong learning as a substitute for initial training. In certain countries, initial training is only weakly related to employability and new entrants to the labour market start at entry-level positions. Vocational training is done primarily in the workplace. However, in other countries, vocational skills are developed through apprenticeships or vocational training schools, which create a better correlation between the labour market and the education system. The first model is used in Southern Europe (Italy, Spain, Portugal and Greece) as well as France, Belgium and Luxembourg, where investment in continuing vocational training is present but much less prevalent than in the second model.

The second model considers continuing education as an extension of initial training. This model is used in the Scandinavian countries (Norway, Finland, Denmark, Sweden), followed by Germany, Australia, Austria, China, the US, Canada, the UK and the Netherlands. In these countries, continuing education is at the heart of the education system with a strong emphasis on vocational training. Moreover, this approach aims to develop and maintain interest in learning among working people in their first years of work, through apprenticeships or the opportunity to earn professional qualifications equivalent to those delivered by the school system. But, it should be noted that this 
training system is to some extent selective in the sense that people with the lowest skill levels are generally excluded. However, a majority of the adult population is able to make good use of the new skills acquired through these programmes (Wolbers, 2005; OECD, 2004; Kasworn, 1993).

\section{Recognition of Experience and Lifelong Learning}

The concept of lifelong learning for adults has been initiated in the 1980s in various countries. In the 1970s, the US experimented with the idea of Prior Learning Assessment (PLA) which led to the project of the Cooperative Assessment of Experiential Learning between 1974 and 1977 (Evans, 2000). It is nowadays managed by the CAEL - Council for Adult and experimental learning - which helps working adults, military and veterans, low-income and unemployed people, employees and older workers return to school by giving them more access to adult-friendly Colleges, recognition for life and work experience, new ways to pay for education.

The idea then spread to several English-speaking countries, under different names: APL (accreditation of prior learning) / APEL (accreditation of prior experiential learning) in the UK; RPL (Recognition of Prior Learning) in Scotland, Ireland, New Zealand, Australia and South Africa; PLAR (prior learning assessment and recognition) in Canada, VAP (validation des acquis professionals) and VAE (validation des acquis d'expérience) in France. Many European countries now offer or are experimenting with recognition of prior learning experience programmes, with four main objectives: officially accredit skills that are not formally recognized; improve employability in tight labour markets, compensate for the preference given to degree-holders in some countries, allow people without easy access to education to obtain degrees and certifications (Konrad, 2000; Colardyn \& Bjornavold, 2004; Duchemin \& Hawley, 2010).

In Europe, in the past two decades, two zones have implemented major initiatives in terms of activity, development and implementation on the recognition of prior experiential learning: England, Wales and Northern Ireland, with the NVQ (National Vocational Qualifications), Scotland with the Scottish Vocational Qualification (SVQ), and France with the VAE, which is unique in that it allows individuals to obtain a full degree for most officially recognised degrees and diplomas (Colardyn \& Bjornavold, 2004; Charraud, 2010; Pougeta \& Osborne 2004; Ansart et al., 2010). These innovative approaches are based on the recognition and assessment of prior experiential learning as an extension of or substitute for adult higher education (Trowler, 1996; Michelson, 1996; Andersson \& Osman 2008).

\section{RESEARCH QUESTIONS AND PROBLEM STATEMENT}

The literature review shows that there are significant differences in the national structures, policies, approaches and realities in terms of adult learners in higher education. Despite these differences, these activities remain rooted in the key principles of lifelong learning, namely that motivated and competent adults must have access to high level specialized knowledge, in keeping with the principle of equal opportunity for adults of all social and economic backgrounds and the principle of excellence in learning through the development of experimental learning methods both in and out of the classroom. For adult education, it is especially important to focus efforts on the recognition of life experiences of all kinds (personal, professional, social, etc.) and the accreditation of prior knowledge and skills (Ansart et al., 2010; Kasworm, 1993; Evans, 2000; Gorringe, 1989).

In the early 2000s, France introduced the Validation des Acquis d'Expérience programme (VAE). Specifically, the Law for Social Modernisation (Loi de Modernisation Sociale) offered a new path to degrees and diplomas of all levels, along with initial training, sandwich programs/courses, and continuing education. This new possibility of obtaining a degree by the accreditation of professional and non-professional experiential learning was something of a revolution in France, due to the paramount importance of degrees, even if this notion dates back only to the early 1980s. Both in the French educational system and on the labour market, having a degree can open all doors. However, the law now states that professional and non-professional experience has the same value as formal education and recognizes that knowledge and skills can be obtained otherwise than via the traditional education systems. 
In this paper, the researchers analyse and discuss lifelong learning in connection with the accreditation of prior experiential learning based on the VAE experiment conducted in France at the university level. Many APEL experiments in Europe in higher education underscore the importance of questioning the relationship between recognition of prior experiential learning and lifelong learning (Armsby et al., 2006; Ansart et al., 2010; Pinte, 2011). This research provides food for thought, especially in the French context, about first, the place of work experience in lifelong learning; second, the links between work experience, higher education and lifelong learning; and third, the meaning and organisation of lifelong learning. Based on these questions, we will analyse how the recognition of prior experiential learning can contribute to lifelong learning, and identify any limitations there may be in the system.

\section{APEL IN FRANCE: FRAMEWORK, EMERGING ISSUES AND CONNECTION TO LIFELONG LEARNING}

\section{The Framework}

VAE is included in the French Labour Code (Article L.900-1) and Education Code (Article L.335-5) as an individual right to the recognition of prior learning. Accreditation of prior experience had been possible through the Validation des Acquis Professionals (VAP), established by the laws of 1985 and 1992 - but it was limited to accrediting levels or just part of the degree, and was based solely on professional experience. VAE introduced a truly novel idea in French society, namely the idea of competence and its social uses in areas such as continuing education, corporate policies, business relations and initial training. This movement, initiated by employers, focuses on experience and achievements in the workplace, and was thought by some to delegitimize academic knowledge and academic certifications. The stated aim of VAE is to reduce social inequalities in education, allowing greater access to degrees, especially for those experiencing the most difficulty on the labour market. The lack of a degree is seen as a barrier in France, where some sort of diploma is required for virtually every job. VAE should remedy this issue and be an additional element supporting the idea of lifelong learning, which is taking hold among academics, the social partners and policy-makers in France, Europe and worldwide.

To draw up an evaluation of VAE in France, various reports issued from the French government and official agencies underline quantitative and qualitative dimensions. In terms of quantitative assessments the "Besson" report (Besson, 2008) and notes produced by DEPP (2011) and DARES (2012) provide rather disappointing figures. Of the 60,000 candidates expected per year, only 26,000 degrees and diplomas were accredited in 2006 (Besson, 2008, p 10.). Moreover, contradicting the objectives of the law, it is not the least skilled people who opt for VAE. It benefits primarily people in managerial positions and intermediary professions (for some $80 \%)$, then employees (18\%) and blue collar workers $(0.2 \%)$. So, a significant quantity of certifications are made at the higher education level (master, license and professional license each account for $20 \%$ of applications), with a special focus $(38 \%)$ on economic sciences, management sciences and social, economic and administrative sciences (DEPP, 2011, p 4).

On the qualitative dimension, the major lesson of the «Besson » report is the impressive loss of candidates at each step of the VAE process (Besson, 2008, p 5). Based on these elements, the "Besson » report addresses several recommendations:

1. Considering the gap between potential and real candidates, it suggests to launch a huge national campaign of information;

2. Considering the loss between people looking for information and the ones deposing an application, it suggests to rationalize the organization of public agencies of certification;

3. Considering the loss between the candidates applying and the ones whose application is accepted, it suggests to reduce the administrative delays and improve candidates' follow up;

4. Considering the loss between the candidates who applied and the final validation, it suggests to improve and facilitate the organization of the VAE jury's (Besson, 2008, p. 6).

Guidance and counseling, starting with the information step to the VAE process guidance step, appear to be a central stake for the development of the VAE. Beyond the information step which is task depending from the State 
agencies, the two other central guidance steps in a VAE process (candidate's guidance and the jury) underline that teachers' competencies and practices require new skills and new capacities (Pinte, 2008; Ansart \& Sanséau, 2012).

\section{Experience as a Source of Learning}

We have seen that the French VAE system is based on the principle that experience is a source of learning. The underlying assumption raises three questions:

1. What is experience in the practice of VAE?

2. How is experience understood, knowing that it is polysemous because it is at once a product, a process and a trajectory?

3. What is the conception of learning as it relates to experience?

The French legislation on VAE does not strictly speaking give a definition of experience. The educational sciences consider the notion of experience as polysemous and open to debate. French VAE holds that experience may be gained in a personal, professional or non-professional context, and that it takes three years to acquire. By not limiting experience to professional contexts, VAE echoes the positions of the US education philosopher Dewey, considered one of the founding fathers of thinking on experience and education. As early as the $1930 \mathrm{~s}$, he stated that experience is life itself. Volunteer, linguistic, sports and parenting experiences are recognized as contexts for skills development (Dewey, 1938).

VAE considers experience above all as a product. VAE candidates must review their past to extract their experiential learning and transform it into skills. VAE analyses a material: the candidates' past and prior experiences. It does not have an educational objective based on experience nor does it attempt to link experience to knowledge, as is often the case in an educational process. However, the literature emphasizes a process of building new learning for the candidate throughout the VAE process, and a result that goes far beyond the mere accreditation of a degree (Armsby et al., 2006; Ben Moussi-Le Gall, 2008; Ansart et al., 2010; Pinte, 2011).

It is also a true personal development process that involves: the construction of an identity: new interpretation and understanding of one's life path, the ability to talk and to define oneself based on one's skills, not just based on job positions or activities; the emergence of a certain self-confidence; a (better) ability to define one's preferences (through aptitudes), and needs in terms of skills and knowledge; development of new capabilities and a new identity: that of a learner, explainer, and self-reflective individual (Ansart \& Sanseau 2012; Ansart et al., 2010).

VAE, because it is itself "experience", is also a source of learning as well as being formative. Certain authors describe it as self-formative. Again, there are similarities with Dewey's approach, who, according to Balleux (2000: 275), believed that "experience acquires a cumulative and unending character that becomes meaningful in the life of the person; because he believes every experience should lead to desirable future experiences". One might think that reflecting on and analysing experience requires a focus on the past, but when seen as a formative process and not just a means to a degree, it also causes candidates to focus on their future.

These practices highlight that there is no systematic link between knowledge and experience, but this link is not necessarily absent in the VAE process. Where it exists, it has the specificity of being diachronic. However, if one believes that learning necessarily requires a dialectical process of interaction between experience and theory, VAE can be formative but with a specific mode and temporality of interaction. One should not confuse the analysis of experience specific to VAE with the practical training involved in initial and continuing education that seeks to link academic knowledge and practical knowledge.

By recognizing all experience - including non-professional - as a source of learning, VAE has several specificities: it creates a learning process exclusively built on experience, with, moreover, an experience prior to the accreditation process; it is not based on linking practical knowledge/academic knowledge (or acquired experience/acquired knowledge) although VAE can deliver degrees available through education, which integrate knowledge. For all that, though VAE is not regarded as a training process, it turns out to be one. 


\section{ANALYSIS AND DISCUSSION}

The lessons learned from VAE in France at the university level can provide valuable input for lifelong learning programmes. French VAE recognises and even officialises experience as a source of learning, training and education. Traditionally, lifelong learning refers essentially to the acquisition of additional knowledge. This field is obviously dealing with adult learners and adults are known to have experience. This should be included as food for thought when considering knowledge taught.

Recognition of prior experiential learning has extended the definition of experience. Experience is not a simple characteristic of group of learners. Experience is not an element to which academic knowledge must be linked. Experience is a material in and of itself, which, before being linked - or subjected - to other sources of learning, must first of all be analysed and optimised. Optimisation means that experience should itself be the source of learning and progression of skills and knowledge of the individual.

Based on the VAE experiment in France at the university level, we can say that a thorough analysis of prior experience first, improves the quality of the experience as a potential source of skills; second, may provide ways to improve the candidate's experiential learning, and third, may help define the direction for lifelong learning.

Therefore, this recognition of prior experiential learning - with the level of detail required by the French VAE system to obtain a degree or diploma - could be the gateway, the catalyst and the vector of lifelong learning. What factors justify this statement? What are the potential difficulties and limitations, and what precautions should be taken when implementing VAE?

\section{Recognition of Prior Experiential Learning as a Catalyst for Lifelong Learning}

Two main arguments support a position advocating a central role for the recognition of prior experiential learning in the lifelong learning process: potentially individualized learning paths, personal empowerment and shorter training times; a focus on experience - and not just professional experience - that is in tune with today's societal changes and the aspirations/constraints of each individual.

The first category of arguments may seem unrelated to the candidate's concerns and interests. This is not the case, or at least not fully the case.

Let's first recall that the recognition of prior experiential learning is a source of learning and progress for the candidate. Thoroughly analysing prior experience is very enriching. For candidates, analysing life experiences involves transforming a material, creating a distance between themselves and their achievements, distinguishing the subject (themselves) from the object (the experience), which they tend to confuse when examining their experiences. Candidates objectify their knowledge (meaning knowledge, skills and attitudes), construct an identity, build recognition (of oneself for oneself, of oneself by others), and gain confidence (in their abilities, in relationships with others, in their life path). The accreditation of experiential learning sets the individual in motion and encourages new capabilities like the ability to learn, to engage in self-reflection or even to be an explainer. These traits seem to be particularly relevant in an information and knowledge society, marked by rapid shifts and demanding more in terms of adaptability.

Recognition of prior experiential learning also specifically echoes the trends of societal needs in general (including businesses and government, and sometimes the individual himself/herself). The approach to adult education has gradually evolved into an individual responsibility for building skills and knowledge, learning, becoming employable and achieving a secure a life path.

Recognition of prior experiential learning may also meet the growing need to reduce training times. By recognizing prior learning, some training components could be revised or eliminated as irrelevant or already learned. The accreditation of prior learning can thus promote individualised learning paths, leading to reduced training time and lower costs. This is obviously of interest to the Government and businesses. However, individuals would also benefit from shorter training times, which would allow them more time for work and personal activities, and enable them to embark on a programme that would otherwise be impossible. 
The second category of arguments is a feature of societal changes, namely the place of work in our lives. This means that an individual's life experience is primarily personal and social rather than professional. This dimension has had three major effects that relate to our discussion: the consideration of non-professional experience is inevitable; this trend toward social and personal activities can promote or discourage individual investment in lifelong learning; recognising non-professional experience can also raise the question of whether it should be taken further, by providing training programmes that do not focus exclusively on knowledge for exclusively professional purposes.

\section{Difficulties and Limitations}

Integrating a process of recognition of experiential learning in lifelong learning, or even, as we mentioned, making it a central element of the process, raises at least four potential difficulties, some of which came up during the French VAE experiment.

First, integrating the recognition of prior experiential learning in lifelong learning can be challenging for some groups of learners, especially poorly qualified learners whose experience is primarily technical or relational. Poorly qualified learners may find the process of expressing it in writing too difficult. Poorly qualified learners may also not see the value of the recognition of prior experiential learning, since they often undervalue their own experience. While lifelong learning may be of interest to them, it is likely that the development of their knowledge through a standard education process will seem more relevant and will lead to the recognition that they often find particularly lacking.

Second, it is a mistake to think that the recognition of prior experiential learning can be an inexpensive form of lifelong learning. The recognition of prior experiential learning is not necessarily less costly than education. One of the major cost components is the guidance provided. For recognition of prior experiential learning to deliver its full potential in the context of lifelong learning, and make individuals responsible for their life path, guidance is essential. VAE experiment shows that high quality guidance requires financial resources. Thus, while individualized learning pathways based on the recognition of prior experiential learning do reduce training times for the different stakeholders, they do not reduce the cost of lifelong learning for funders. Therefore, the arguments for introducing a process of recognition of prior experiential learning should not be based primarily on cost issues.

Third, one may ask whether it is necessary to link the recognition of experiential learning to a degree or diploma. This question makes all the more sense in the Anglosphere where degrees and diplomas are much less important than in France, considering more the status of the diplomas than the employability or career development dimensions. Linking the recognition of experiential learning to a degree or diploma has advantages and disadvantages.

Let's start with the disadvantages that have been widely seen by the French experiment: difficulties in the definition of standards, debate on the place of academic knowledge, difficulties in the definition of training programmes and degrees, difficulties for candidates to immerse themselves in an approach based on standards of knowledge. Not linking prior experiential learning to a degree or diploma may avoid some of these difficulties. This might result in lower requirements in terms of the deliverable, which would probably be detrimental to the analysis of the experience and to the expected effects on individuals.

The fourth and final point is the risk that lifelong learning may become overly "professionalised", through the introduction of recognition of prior experiential learning and its potentially central role. Recognition of experience could support an extreme position calling into question the value of academic knowledge. Indeed, despite the fact that non-professional experience is eligible for recognition of prior learning, it is quite possible that the areas developed will be centred primarily on professional experience. This concern may lead to focusing lifelong learning on experience and skills almost exclusively dedicated to performance in the workplace. More generic or more academic knowledge in this case would be left by the wayside. This would mean losing the ability to adapt and learn new skills that academic knowledge supposedly confers. Therefore, lifelong learning actors must certainly be careful not to disqualify academic knowledge on the pretext of wanting to promote experience. In light of this risk, it might be better to maintain a link with degrees and diplomas, since they are also awarded through the ordinary educational process and are defined by standards of knowledge. 


\section{CONCLUSION}

Lifelong learning is a concept that must remain extremely vibrant and dynamic. It is a key factor for success in developing a knowledge society, which is an aim of many countries worldwide. In this paper, the researchers' goal is also to encourage actors concerned with lifelong learning to look at the issues from a different perspective. Indeed, it seems safe to continue on the known and well-travelled path. History shows, however, that in the field of education and training, the risks of doing so are significant.

The French VAE shows how a system for recognising experience in areas such as work, labour unions, volunteer organizations, linguistic endeavours, etc. can provide food for thought and reconfigure the predominant approaches to lifelong learning. Turning experience into experiential learning has enormous potential as a source of learning. French VAE analysis underlines that experience is a source of learning and therefore it is formative. But it goes much further than that. This learning that brings forth a new actor from the individual is not neutral. Indeed, it goes far beyond an accreditation of knowledge and/or skills and learning. It is the process, the journey of the candidate who achieves a new vision of himself/herself that gives lifelong learning a different perspective.

Recognition of prior experiential learning is much more than another pathway to a degree or another tool available to educational institutions and learners. As discussed in this article, it can lie at the very heart of the lifelong learning process. It has several key characteristics for this: individualized learning pathways, personal development and empowerment of the candidates, shorter training times, and a focus on several types of experiences that are directly related to societal and social changes. For countries that have already established systems for the recognition of experiential learning, there seems to be a strong incentive to enhance or even reorient their approaches to lifelong learning. Such an enhancement would provide greater flexibility during periods of economic turmoil and high unemployment, and provide new resources in terms of information and knowledge for the future.

\section{AUTHOR INFORMATION}

Pierre-Yves Sanséau is Professor at Grenoble Ecole de Management, France. He holds a Ph.D. in Business Administration from the University of Lyon (France), a MBA (Montreal, Canada) and a M.Sc. in Political Sciences. His research interests include international education management, lifelong learning, management of competences, working time, work-life balance. He is author of various contributions on Accreditation of prior experience learning. E-mail: pierre-yves.sanseau@grenoble-em.com (Corresponding author)

Sandrine Ansart is Professor at Grenoble Ecole de Management, France. She holds a Ph.D. in International Economy. Dr Ansart is a specialist in the fields of Cognitive Process and Pedagogy, and Information and Knowledge Economics. She has published several articles on these themes and she is the co-author of a book on Accreditation of prior experience learning.

\section{REFERENCES}

1. Andersson, P., Fejes, A. and Song-Ee A, (2004). Recognition of Prior Vocational Learning in Sweden. Studies in the Education of Adults, (36), 1, 57-71.

2. Andersson, P., and Fejes, A., (2005). Recognition of prior learning as a technique for fabricating the adult learner: a genealogical analysis on Swedish adult education policy. Journal of Education Policy, Vol. 20, No. 5, 595-613.

3. Andersson, P., and Osman, A., (2008). Recognition of Prior Learning as a Practice for Differential Inclusion and Exclusion of Immigrants in Sweden. Adult Education Quarterly, November, vol. 59 no. 1, 42-60.

4. Ansart, S., Sanséau, P.-Y, (2012). L'accompagnement dans un processus VAE basé sur un référentiel de compétences: de l'enjeu de l'introspection aux possibles apports du coaching. Carrierologie, 12, $\mathrm{N}^{\circ} 3-4$.

5. Ansart, S., Sanséau, P.-Y., and Lefort, P., (2010), La VAE, un outil de développement des compétences. Paris: Dunod.

6. Armsby, P., Costley, C. and Garnett, J., (2006). The legitimisation of knowledge: a work-based learning perspective of APEL. International Journal of Lifelong Education, 25-4,369-383. 
7. Arulampalam, W., Booth, A. L., and Bryan, M. L., (2004). Training in Europe. Journal of the European Economic Association, 2(2-3), 346-360.

8. Balleux, A., (2000). Evolution de la notion d'apprentissage expérientiel en éducation des adultes: vingtcinq ans de recherche. Revue des Sciences de l'Education, XXVI, 2, 263-285.

9. Ben Moussi-Le Gall, L., (2008). Validation des Acquis de l'Expérience. Retour d'expériences à l'université. Paris: L'Harmattan.

10. Besson, E., (2008). Valoriser l'acquis de l'expérience: une évaluation du dispositif de VAE, Rapport auprès du Gouvernement Français. Paris: La Documentation Française.

11. Charraud, A. M., (2010). European Inventory on Validation of Non-formal and Informal Learning 2010. Country Report: France. European Centre for the Development of Vocational Training.

12. Colardyn, D., and Bjornavold, J., (2004). Validation of Formal, Non-Formal and Informal Learning: policy and practices in EU Member States. European Journal of Education, 39-1, 69-89.

13. Commission of the European Communities, (2000). A Memorandum on Lifelong Learning. Brussels: SEC, $1832 \mathrm{p}$.

14. DARES (2012). «La vae en 2010 dans les ministères certificateurs», n 037, http://travailemploi.gouv.fr/IMG/pdf/2012-037.pdf

15. DEPP (2011). «La validation des acquis de l'expérience (VAE) dans les établissements d'enseignement supérieur en 2010». Gouvernement français, Note d'information 11-30, décembre.

16. Dewey, J., (1938). Expérience et Education. Paris: Armand Colin.

17. Duchemin, C., and Hawley, J., (2010). European Inventory on Validation of Non-formal and Informal Learning 2010. Thematic Report - Validation in the Higher Education Sector. European Centre for the Development of Vocational Training.

18. Education, Audiovisual and Culture Executive Agency, (2012). The European Higher Education Area in 2012. Bologna Process Implementation Report. http://eacea.ec.europa.eu/education/eurydice

19. Evans, N., (2000). AP(E)L, why, where, how? Setting the international scene. In N. Evans (ed.), Experiential Learning Around the World: Employability and the Global Economy. London: Jessica Kingsley Publishers, pp. 15-30.

20. Gorringe, R., (1989). Accreditation of Prior Learning Achievements: Developments in Britain and Lessons from the USA. Coombe Lodge Report, 21-5 1989.

21. Kasworm, C. E., (1993). Adult Education from an International Perspective. Higher Education, 25-4, 411423.

22. Konrad, J., (2000). Assessment and Verification of National Vocational Qualifications: policy and practice. Journal of Vocational Education and Training, 52, 2, 225-242.

23. Lee, M., and Friedrich, T., (2011). Continuously reaffirmed, subtly accommodated, obviously missing and fallaciously critiqued: ideologies in UNESCO's lifelong learning policy. International Journal of Lifelong Education, 30-2, 151-69.

24. Maillard, F., and Rose, J., (2007). Les diplômes de l'Education nationale dans l'univers des certifications professionnelles : Nouvelles normes et nouveaux enjeux. Relief, $n$ 20, Mars.

25. Müller, W. and Wolbers, M. H. J., (2003). Educational Attainment in the European Union: Recent trends in Qualifications Patterns. In Transitions from Education to Work in Europe. The integration of Youth into EU labour Markets, ed. by W. Müller and M. Gangl. Oxford: Oxford University Press, pp. 23-62.

26. Norman, E., (1992). Experiential Learning: Its Assessment and Accreditation. London Routledge: Chapman and Hall.

27. Organisation for Economic Co-operation and Development (OECD) (2004). Lifelong learning. Policy Brief. Paris: OECD.

28. Papastamatis, A., and Panitsidou, E., (2009). The aspect of 'accessibility' in the light of European lifelong learning strategies: Adult education centres - a case study. International Journal of Lifelong Education, 286-3, 335-351.

29. Pinte, G., (2011), L'expérience et ses acquis -Bilan et Perspectives pour l'éducation et la formation. Paris: L'Harmattan.

30. Pinte, G., (2008). Quelle professionnalisation pour les accompagnateurs en VAE ? Actualité de la formation permanente, 216, pp 55-62.

31. Pouget, M., and Osborne, M., (2004). Accreditation or validation of prior experiential learning: knowledge and savoirs in France-a different perspective? Studies in Continuing Education, Volume 26, Issue 1, 45-66. 
32. Stenfors-Hayes, T., Griffiths, Ch., and Ogunleye, J., (2008). Lifelong learning for all? Policies, barriers and practical reality for a socially excluded group. International Journal of Lifelong Education, 27-6, 625-40.

33. Sultana, R. G., (2004). Guidance policies in the knowledge society: Trends, challenges and responses across Europe. Thessaloniki, Greece: European Centre for the Development of Vocational Training.

34. Tuschling, A., and Engemann, Ch., (2006). From Education to Lifelong Learning: The emerging regime of learning in the European Union. Educational Philosophy and Theory, 38-4, 451-469.

35. Trowler, P., (1996). Angels in marble? Accrediting prior experiential learning in higher education. Studies in Higher Education, 21-1.

36. Tuijinman, A., (1997). Economics of Adult Education and Training. Adult Education and Development, 49(2), 189-198.

37. Watts, A. G., and Fretwell, G., (2004). Public policies for career development: Policy strategies for designing career information and guidance systems in middle-income and transition economies. Washington, DC: World Bank.

38. Watts, A. G. and Sultana, R. G., (2004). Career guidance policies in 37 countries: Contrasts and common themes. International Journal for Educational and Vocational Guidance, 4, 105-122.

39. Werquin, P., (2010). Recognising Non-Formal and Informal learning, Outcomes, Policies and Practices. Paris: OECD Publishing.

40. Wolbers, M. H. J., (2005). Initial and Further Education: Substitutes or Complements? Differences in Continuing Education and Training over the Life-Course of European Workers. International Review of Education, 51, 5-6, 459-478. 


\section{NOTES}

